\title{
Hereditary Nonmelanoma Skin Cancer
}

\author{
Vasiliki Nikolaou, MD,* Alexander J. Stratigos, MD,* and Hensin Tsao, MD, PhD ${ }^{\dagger}$
}

\begin{abstract}
Cutaneous basal and squamous cell carcinomas are among the most frequent malignancies in the white population, with the annual incidence estimates ranging from 1 million to 3.5 million cases in the United States. These tumors can occur either sporadically or in the context of hereditary genodermatoses with cancer predisposition, such as basal cell nevus syndrome, xeroderma pigmentosum, epidermolysis bullosa, or oculocutaneous albinism. Different genes and signaling pathways have been shown to play a central role in the development and growth of these tumors. This article overviews the clinical features, diagnostic criteria, and the most recent data on genetic routes of the major hereditary syndromes predisposed to the development of nonmelanoma skin cancer.
\end{abstract}

Semin Cutan Med Surg 31:204-210 (C) 2012 Frontline Medical Communications

KEYWORDS BCC, SCC, basal cell nevus syndrome, xeroderma pigmentosum, hereditary cancer syndromes

$\mathrm{N}$ onmelanoma skin cancer is one of the most common malignancies among white populations, accounting for $>2$ million cases currently treated in the United States. ${ }^{1}$ Although several environmental exposure factors, such as ultraviolet radiation (UVR), radiotherapy, viral infections, or immunosuppression, have been most strongly associated with skin tumor development, there remains a minority of cases where basal cell carcinomas (BCCs) or squamous cell carcinomas (SCCs) occur in the setting of hereditary cancer syndromes (Table 1). This article attempts to provide an overview of the recent data concerning genetic syndromes that predispose to BCC or SCC development.

\footnotetext{
*Dermato-Oncology Unit, Department of Dermatology, University of Athens Medical School, Andreas Sygros Hospital, Athens, Greece.

$\uparrow$ Department of Dermatology, Wellman Center for Photomedicine, Massachusetts General Hospital Cancer Center, Massachusetts General Hospital, Boston, MA

Funding/Support: This activity was supported in part by the United States National Institutes of Health (K24 CA149202) and by the generous donors to the MGH Millennium Melanoma Fund.

Conflict of Interest Disclosures: The authors have completed and submitted the ICMJE form for disclosure of potential conflicts of interest. Drs Nikolaou and Stratigos have no conflicts to report. Dr Tsao has received compensation for Board membership from Journal Watch; consultancy services for Scibase, Quest, World Care Clinical, and Genenteh. Dr Tsao's institution has grants or grants pending with National Institutes of Health, Department of Defense, American Skin Association, Melanoma Research Alliance and Cephalon. Dr Tsao has received royalties from Up to Date and compensation for travel from Pacific Dermatology Association and Cutaneous Malignancies.

Correspondence Author: Hensin Tsao, MD, PhD, Department of Dermatology Wellman Center for Photomedicine, Massachusetts General Hospital Cancer Center, 55 Fruit Street, Boston, MA. E-mail: htsao@partners.org
}

\section{Hereditary Basal Cell Carcinomas}

\section{Basal Cell Nevus Syndrome (Gorlin Syndrome, Gorlin-Goltz Syndrome)}

Basal Cell Nevus Syndrome (BCNS) is an autosomal dominant disorder, mainly characterized by the development in early life of multiple BCCs. The estimated prevalence of the disease is 1 case per 56,000-164,000, without any gender predominance. Typically, there is a relevant family history, although sporadic mutations have been reported in approximately 20\%-30\% of all cases.

A number of different clinical signs may be associated with Gorlin syndrome, including BCCs, odontogenic cysts, palmar and plantar pits, and ectopic calcifications of the falx cerebri. BCCs may first appear as early as within the first year of life up to the mid-thirties, with a median age of onset of 20 years. ${ }^{2,3}$ Patients with BCNS may present with as few as 1 to $>100$ BCC tumors with a median number of $8 .{ }^{2}$ Clinically, the latter usually involves symmetrically distributed skincolored or hyperpigmented papules or nodules, with or without ulceration, having a maximum diameter of 1-10 mm, although occasionally they are similar to acrochordons or vascular lesions. Secondary signs, such as ulceration, bleeding, or crusting, seem to occur rarely before adolescence. The face, neck, and trunk areas are the most commonly affected. Patients with darker skin pigmentation, such as those of African or Mediterranean origin, develop significantly fewer BCCs, suggesting that skin pigmentation may act protectively against the mutagenic effects of UVR even in genetically predisposed individuals.., 5 
Table 1 Inherited Diseases With Manifestations of NMSC, Categorized by Presenting Type of Tumor (SCC/BCC). Information from the National Cancer Institute Database, http://www.cancer.gov

\begin{tabular}{|c|c|c|c|c|}
\hline Condition & Gene & Locus & $\begin{array}{l}\text { Pattern of } \\
\text { Transmission }\end{array}$ & Function \\
\hline \multicolumn{5}{|c|}{ SQUAMOUS CELL CARCINOMA } \\
\hline \multirow[t]{2}{*}{ Xeroderma pigmentosum } & XPA-XPG & $\begin{array}{l}9 q 34.1,2 q 21,3 p 25.1,19 q 13.2,11 q 12-13 \text { and } \\
11 p 11-12,16 p 13.3,13 q 32-33\end{array}$ & AR & Nucleotide excision repair \\
\hline & $X P V$ & $6 \mathrm{p} 21$ & & $\begin{array}{l}\text { Replication of damaged DNA on the } \\
\text { leading strand }\end{array}$ \\
\hline Ferguson-Smith syndrome & TGFBR1 & $9 q 22.3$ & AD & Growth factor signaling \\
\hline Oculocutaneous albinism & TYR, OCA2, MATP/OCA4, TYRP1 & $11 q 14.3,15 q 11.2-q 12,5 p 13.3,9 p 23$ & AR & Melanin synthesis \\
\hline \multicolumn{5}{|l|}{ Epidermolysis bullosa } \\
\hline Dystrophic & COL7A1 & $3 p 21.3$ & AR, AD & $\begin{array}{l}\text { Collagen anchor of basement } \\
\text { membrane to dermis }\end{array}$ \\
\hline Junctional & LAMA3, LAMB3, LAMC2, COL17A1 & $\begin{array}{l}18 q 11.2,1 q 32 \\
1 q 25-q 31,10 q 24.3\end{array}$ & AR & Connective tissue \\
\hline Epidermodysplasia verruciformis & EVER1, EVER2 & $17 q 25$ & $\mathrm{AR}, \mathrm{AD}$ & $\begin{array}{l}\text { Signal transduction in endoplasmic } \\
\text { reticulum }\end{array}$ \\
\hline Fanconi anemia & $\begin{array}{l}\text { FANCA, FANCB, FANCC, FANCD1/BRCA2, } \\
\text { FANCD2, FANCE, FANCF, FANCG/ } \\
\text { XRCC9, FANCI, FANCJ/BRIP1, FANCL, } \\
\text { FANCM, FANCN/PALB2 }\end{array}$ & $\begin{array}{l}16 q 24.3, \text { Xp22.31, 9q22.3, 13q12.3, 3p25.3 } \\
6 \mathrm{p} 21.3,11 \mathrm{p} 15,9 \mathrm{p} 13,15 \mathrm{q} 25-26,17 \mathrm{q} 22.3 \\
2 \mathrm{p} 16.1,14 \mathrm{q} 21.3,16 \mathrm{p} 12.1\end{array}$ & AR, XLR & DNA repair \\
\hline Dyskeratosis congenital & $\begin{array}{l}\text { DKC1, } \\
\text { TERC, } \\
\text { TINF2, } \\
\text { NHP2/NOLA2, } \\
\text { NOP10/NOLA3, } \\
\text { TERT, WRAP53 }\end{array}$ & $\begin{array}{l}X q 28 \\
3 q 21-q 28 \\
14 q 12 \\
5 q 35.3 \\
15 q 14-q 15 \\
5 q 15.33\end{array}$ & $\begin{array}{l}\text { XLR } \\
A D \\
A R \\
A R \\
A R, A D\end{array}$ & Telomere maintenance and trafficking \\
\hline Rothmund-Thomson syndrome & RECQL4, C16orf57 & $8 q 24.3,16 q 13$ & AR & Telomere maintenance and trafficking \\
\hline Bloom syndrome & BLM/RECQL3 & $15 q 26.1$ & $\overline{A R}$ & Chromosomal stability \\
\hline Werner syndrome & WRN/RECQL2 & $8 p 12-p 11.2$ & AR & Chromosomal stability \\
\hline \multicolumn{5}{|c|}{ BASAL CELL CARCINOMA } \\
\hline Basal cell nevus syndrome & $\begin{array}{l}\text { PTCH1 } \\
\text { PTCH2 }\end{array}$ & $\begin{array}{l}9 q 22.3-q 31 \\
3.597-6.457\end{array}$ & $\begin{array}{l}\mathrm{AD} \\
\mathrm{AD}\end{array}$ & $\begin{array}{l}\text { Component of the hedgehog } \\
\text { signaling pathway }\end{array}$ \\
\hline Rombo syndrome & Unknown & & AD & $\begin{array}{l}\text { DNA repair and cell cycle } \\
\text { regulation? }\end{array}$ \\
\hline Bazex-Dupre-Christol syndrome & Unknown & Xq24-27 & XLD & \\
\hline
\end{tabular}

$\mathrm{AD}$, autosomal dominant, $\mathrm{X}$-linked recessive; $\mathrm{AR}$, autosomal recessive; $\mathrm{BCC}$, basal cell carcinoma; NMSC, nonmelanoma skin cancer; SCC, squamous cell carcinoma. 


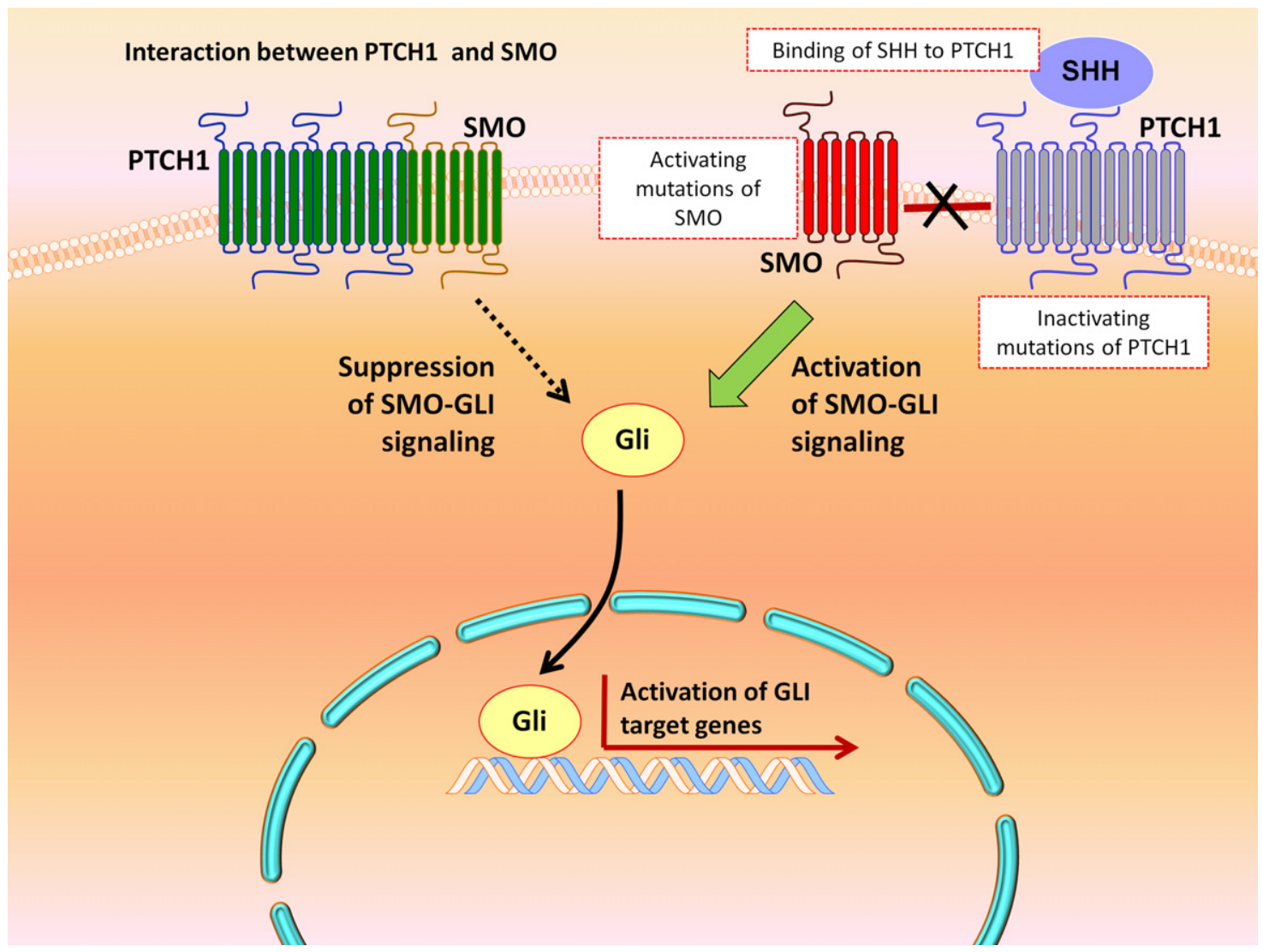

Figure 1 The main constituents of the Sonic Hedgehog (SHH) pathway include the SHH ligand and the transmembrane proteins PTCHI and SMO. In the absence of SHH, PTCH1 interacts with SMO and suppresses SMO-mediated signaling. Binding of SHH to PTCH1, gain of function mutations of SMO, or inactivating mutations of PTCH1 inhibit PTCH1-mediated suppression allowing SMO to transduce a growth signal to the nucleus via the complex of gliomaassociated oncogene homolog (GLI) transcription factors. These factors activate a number of target genes that promote cell growth and proliferation.

Plantar pits constitute another major feature of BCNS and occur in approximately $80 \%$ of patients. ${ }^{3}$ They are a valuable clinical sign although they are often overlooked during physical examination. They arise as tiny depressions, $2-3 \mathrm{~mm}$ in diameter and $1-3 \mathrm{~mm}$ in depth located on the palms and the soles. The pits are more visible if the hands have been previously soaked in water for approximately 10 minutes. Dermoscopy improves the visualization of these lesions, demonstrating the characteristic presence of red globules inside slightly depressed lesions. ${ }^{6}$ Minor skin manifestations include epidermal, sebaceous, meibomian cysts, or facial milia, as well as discrete patches of unusually long-pigmented hair. ${ }^{7}$

Apart from BCCs, patients with BCNS are at increased risk of developing other malignancies, especially medulloblastomas. Other neoplasms include meningiomas, sarcomas, cardiac and ovarian fibromas, and ovarian desmoids. The disease is also characterized by ectopic intracranial calcification of the falx cerebri (in approximately $65 \%$ of patients), congenital skeletal abnormalities, macrocephaly and frontal bossing, cleft lip and/or palate, and eye anomalies.

Another major feature of BCNS is the odontogenic kerato- cysts of the jaw occurring in 65\%-100\% of patients. ${ }^{2,8}$ They appear at a mean age of 15 years and, although in many cases they remain asymptomatic, they can frequently occur with swelling, pain, displaced or impacted teeth, or an unusual taste after the rupture of a cyst. In the vast majority of cases, odontogenic keratocysts are multiple, ranging from 1 to 30 .

The molecular basis of BCNS and the role of the Sonic Hedgehog (SHH) signaling, an important pathway of embryonic development, has been recently elucidated. Germ-line mutations of the patched gene (and its human homologue Patched, PTCH), one of the major components of this pathway and tumor suppressor gene, have been identified as the primary cause of BCNS. The PTCH gene is located on chromosome 9q22-31 and encodes for the transmembrane glycoprotein that acts as a membrane receptor for the SHH signal. Under normal conditions, the PTCH protein binds to a second transmembrane protein (smoothened, SMO). PTCH inhibits SMO and acts as a cell cycle regulator, by blocking downstream events that result in transcriptional activation of target genes (Fig. 1). This patched-mediated inhibition of smoothened can be relieved when soluble SHH binds to $\mathrm{PTCH}$. This results in activation of the Hedgehog pathway 
and affects downstream events, such as cell growth and differentiation. Inactivation of PTCH or activating mutations of SMO lead to increased smoothened signaling and growth promotion with subsequent neoplasm development. ${ }^{9}$

Genetic analysis of patients with Gorlin syndrome has identified deletions, insertions, splice-site alterations, and nonsense and missense mutations of the PTCH gene. ${ }^{10,11}$ Currently, there is a firm and reproducible genotype/phenotype correlation among Gorlin syndrome patients. In a recent review of 202 patients and 62 families, Jones et a ${ }^{12}$ failed to detect any association between the presence of the PTCH mutation or a mutation type and the age of onset or the total number of BCCs.

\section{Rombo Syndrome}

Rombo syndrome was first described in 1981 by Michaëlsson et $\mathrm{al}^{13}$ as a disorder characterized by acral erythema, vellus hair cysts or similar lesions, hypotrichosis, and vermiculate atrophoderma. ${ }^{13}$ The authors, studying a single family, described a male-to-male transmission and suggested an autosomal dominant pattern of inheritance. Since then, 2 additional cases have been reported. ${ }^{14,15}$ Concerning the first of the latter 2, described by Ashinoff et al, ${ }^{14}$ the diagnosis of Rombo syndrome was strongly challenged, whereas the second, described by van Steensel et al, ${ }^{15}$ was subsequently found to be identical to the one reported in 1981 .

Affected skin shows histological abnormalities resembling solar elastosis, suggesting that the genetic component of Rombo syndrome may be involved in DNA repair and cellcycle regulation. BCCs may develop during adulthood, although the exact age at onset probably depends on environmental factors, such as UVR exposure.

\section{Bazex-Dupre-Christol Syndrome}

Bazex-Dupre-Christol syndrome (BDCS) is an X-linked dominant disorder characterized by hypotrichosis, follicular atrophoderma of the cheeks, milia cysts, and BCCs. Hypohidrosis, trichoepitheliomas, and facial hyperpigmentation may also occur, but less frequently. Hypotrichosis is usually the earliest sign appearing after birth, whereas during childhood, most of the symptoms have already developed. BCCs usually appear after the first decade of life, although 2 cases were reported involving 3- and 5-year old females. ${ }^{16}$ In 1995, Vabres et $\mathrm{al}^{17}$ reported a linkage of 3 families to a 23.3-Mb region on chromosome Xq24-27.1. These findings were later supported by Parren et al who reported to have narrowed down the critical region further, to an 11.4-Mb interval on the same chromosome.

Oley syndrome is a clinical entity first described in 1992. Oley et al ${ }^{18}$ studied a family whose affected members had clinical presentation identical to BDCS but symptoms regressed during adulthood. A second family was also reported in 2000, but based on the overlap of clinical characteristics between affected members' presentation and BDCS, the authors suggested that the 2 syndromes are most probably variants of the same disease. ${ }^{19}$

\section{Hereditary Squamous Cell Carcinoma}

\section{Xeroderma Pigmentosum}

Xeroderma pigmentosum (XP) is a group of related genetic disorders, clinically characterized by early development of skin tumors, mainly in sun-exposed skin. The disease is inherited in an autosomal recessive manner, while its prevalence has been estimated at 1:250,000 in the United States.

In affected newborns, the skin is normal; however, unusually prominent sunburn reactions can be noted during infancy. From early childhood, patients develop multiple skin tumors as well as premature skin aging, photophobia, and pigmentary changes. Patients who are not protected from sun exposure develop BCCs or SCCs at a median age of 8-9 years. Patients have a 1000-fold increased risk for cutaneous malignancies compared with the general population, mainly developed on sun-exposed areas. Nonmelanoma skin cancers develop at an average age of 8 years, whereas other actinic damages, such as actinic keratosis and poikiloderma, may appear.

Various internal cancers have been also reported in XP patients, who are considered to be at a significantly increased risk of developing lung, breast, pancreatic, gastric, and brain cancers as well as leukemia. Extracutaneous signs may occur, including ophthalmic and neurologic anomalies, such as microcephaly, progressive sensorineural hearing loss, cognitive impairment, ectropion, and corneal opacification.

The disease is caused by mutational changes in genes encoding for proteins involved in the nucleotide excision repair pathway. A total of $8 \mathrm{XP}$ genes have been identified that are involved in nucleotide excision repair. Based on these genes, the disease is subdivided into 7 subgroups (xeroderma pigmentation complementation groups A-G [XPA-XPG] and XP variant $[X P V]$ genes) with discrete clinical characteristics. For example, patients with XPA or XPC mutations share similar skin findings; however, XPA mutation patients may also have neurologic impairment.

\section{Ferguson-Smith Syndrome}

Multiple self-healing squamous epitheliomas or FergusonSmith syndrome is an autosomal-dominant disease, characterized by self-healing skin tumors that are pathologically indistinguishable to SCCs. Patients present with keratoacanthoma-like tumors, located typically in light-exposed skin areas and often being locally destructive. The growth phase of tumors lasts for a few weeks, to be followed by the regression phase, which ends up leaving pitted scars at the site of resolved tumors. Germ line variants in the transforming growth factor beta receptor 1 (TGFBR1) gene on chromosome 9 have been identified in patients with this condition. Loss-of-function mutations in the TGFBR1 gene, including changes in the extracellular ligand-binding domain and truncating mutations in the kinase domain, have been detected in 18 of 22 affected families with Ferguson-Smith syndrome. ${ }^{20}$ Germ line alterations in TGFBR1 have also been described in an aortic aneurysm syndrome (Loeys-Dietz syndrome), al- 
though the changes activate TGFBR1 in Loeys-Dietz syndrome and inactivate TGFBRl in multiple self-healing squamous epitheliomas syndrome.

\section{Rothmund-Thomson Syndrome}

Rothmund-Thomson syndrome is an autosomal recessive disorder characterized by widespread erythema, swelling, and blistering, arising in the first 6 months of life and gradually resulting in poikiloderma over the first year. Plantar hyperkeratotic lesions, sparse hair, cataracts, short stature, and bone defects may occur. Patients are at high risk of developing nonmelanoma skin cancers, as well as osteosarcoma. The prevalence of BCCs and SCCs in young individuals has been estimated to be $2 \%$ and $5 \%$, respectively. ${ }^{21}$

The disease is caused by mutations in the ReQ protein-like 4 gene (RECQL4 gene), which encodes a RecQ DNA helicase. DNA helicases are enzymes that unwind DNA and are involved in basic cellular processes, such as replication, transcription, and repair. A genotype/phenotype analysis in 33 Rothmund-Thomson syndrome patients showed that the presence of truncating mutations in RECQL4 is associated with a higher risk of osteosarcoma and suggested 2 different types of the disorder. The first type is associated with the characteristic cutaneous findings in the absence of osteosarcomas, whereas the second is characterized by poikiloderma as well as an increased risk of osteosarcoma and deleterious mutations in RECQL4. ${ }^{22}$

\section{Fanconi Anemia}

Fanconi anemia (FA) is an autosomal recessive disorderwith the exception of a rare X-linked form-characterized by bone marrow failure, developmental defects, and increased cancer risk. Patients mainly develop hematological abnormalities, which are already present in the majority of cases by the age of 40 . Leukemia is the most commonly reported cancer, but solid tumors as well as SCC of the skin are also commonly diagnosed. The estimated cumulative probability of development of a solid tumor in FA patients is $76 \%$ by the age of 45 years. ${ }^{23}$ Other clinical features include kidney and cardiovascular abnormalities and developmental delay, hyper-reflexia, central nervous system (CNS) arterial malformation, stenosis of the internal carotid artery, and the hypoplastic pituitary gland. Cutaneous signs include hyperpigmented mottling, café-au-lait macules, and small areas of hypopigmentation. ${ }^{24,25}$ Thirteen loci have been identified for FA.

\section{Oculocutaneous Albinism}

Oculocutaneous albinism (OCA) is a rare group of genetic disorders, characterized by the complete or partial absence of pigmentation in the skin, hair, and eyes. A total of 4 types of albinism have been identified, each of them resulting from specific mutations in a single gene, named: Tyrosinase (TYR), Oculocutaneous Albinism 2 (OCA2), Tyrosinase-related Protein 1 (TYRP1), and Solute Carrier Family 45, Member 2-SLC45A2, respectively.

The association of cutaneous carcinomas and OCA has been confirmed in 2 types of the disease, OCA1 and OCA2.
OCAl is subdivided into 2 categories: (1) OCAlA is considered to be the most severe type of albinism and is characterized by absolute absence of melanin synthesis in any tissue; and (2) OCA1B is associated with variable levels of pigmentation in the hair, skin, and eyes. Most patients are compound heterozygotes with OCAl cases harboring mutations in the tyrosinase gene, which encodes for TYR. TYR is a coppercontaining enzyme catalyzing the first 2 steps in the melanin biosynthesis pathway, converting tyrosine to L-3,4-dihydroxyphenylalanine and subsequently to L-3,4-dihydroxyphenylalanine-quinone. Patients with OCAl carry mutations that completely or partially eliminate the enzyme's activity, corresponding to the OCA1A and OCAlB phenotypes, respectively. OCA2 encodes for P-protein that is located in the membrane of melanosomes, and its function remains unknown. It has been proposed that the P-protein may regulate the $\mathrm{pH}$ of the melanosome. ${ }^{26}$

SCC is the most common skin tumor among OCA patients. The results of a 2-year follow-up of 350 albinos from a local registry in Tanzania reported a total number of 104 cutaneous malignancies, with 100 SCCs, 3 BCCs, and 1 melanoma. ${ }^{27}$ Skin cancers have been also reported in other albinism syndromes, such as Hermansky-Pudlak syndrome, Chediak-Higashi syndrome, and Griscelli syndrome.

\section{Epidermolysis Bullosa}

Epidermolysis bullosa (EB) comprises a group of genodermatosis disorders, characterized by skin fragility and blistering. The dystrophic and junctional types have been associated with SCC development. The majority of the dystrophic-type patients of EB carry a germ-line mutation in the Collagen, type VII, alphal (COL7A1) gene. This gene encodes for type VII collagen, which is the main component of anchoring fibrils. The latter are the molecules that form a structural link between the basement membrane and the dermis, providing stability and resistance to skin trauma. ${ }^{28}$ The deficiency in anchoring fibrils leads to severe blistering, skin atrophy, and scarring. Dystrophic EB-causing mutations can be either dominant or recessive, leading to 2 recessively inherited subtypes: (1) severe generalized (Hallopeau-Siemens type) and generalized-other (non-Hallopeau-Siemens type), and (2) a dominantly inherited form, the dominant dystrophic EB. Patients of the severe generalized subtype are at a high risk to develop SCC. Data from the National EB Registry in the US ${ }^{29}$ have shown that by the age of 45 , approximately $85 \%$ of all patients with a severe generalized subtype of EB will have developed at least 1 cutaneous SCC, whereas the cumulative risk by the age of 20 is $6 \%$. SCCs tend to metastasize, leading to death within 5 years of initial diagnosis. ${ }^{30}$

Junctional epidermolysis bullosa is a rare recessive type of the disease related to significant mortality rates of $50 \%$ within the first year of life. It is caused by mutational changes in the encoding genes of the 3 basic subunits of the epidermal basement membrane of an adhesion protein named Laminin 332. The Herlitz type of junctional-epidermolysis bullosa is characterized by extensive and destructive blistering of the skin 
and mucous membranes, and is associated with an $8 \% \mathrm{cu}-$ mulative risk of developing SCC by the age of $25 .{ }^{31}$

The mechanism by which type VII collagen defects engender SCCs is still unclear. One recent study found that matrix composition in patients with recessive dystrophic epidermolysis bullosa (RDEB) may promote tumor development and that type VII collagen directly modulates proteins elaborated by dermal- and cancer-associated fibroblasts. ${ }^{32}$

\section{Epidermodysplasia Verruciformis}

Epidermodysplasia verruciformis-also called LewandowskyLutz dysplasia-is a rare heritable disorder characterized by abnormal skin susceptibility to human papillomavirus (HPV) infections. Patients develop generalized nonresolving verrucous lesions after infection with certain HPV subtypes, developing into SCC in about half of the cases. Inactivating mutations of either the Epidermodysplasia Verruciformis 1 (EVER1) or EVER2 genes have been reported to be causal for epidermodysplasia verruciformis. ${ }^{33}$ Both of these genes are located on 17q25.3 and encoded for proteins that regulate the zinc homeostasis. These proteins form a complex with the zinc transporter 1, which, in turn, is blocked by certain HPV proteins.

\section{Dyskeratosis Congenita}

Dyskeratosis congenita-also called Zinsser-Cole-Engman disease-is a progressive bone marrow failure syndrome that is characterized by dysplastic nails, reticulated pigmentation, and oral leukoplakia. Other cutaneous findings include alopecia, premature graying of the hair, hyperkeratosis of the palms and soles, and adermatoglyphia. Of these patients, 90\% have peripheral cytopenia of one or more blood-cell lines and are at a markedly increased risk of acute leukemia and bone marrow failure. There is also an increased prevalence of mucosal SCCs located in the buccal mucosa, nasopharynx, esophagus, rectum, vagina, and cervix. Cutaneous SCC s have been reported in 1.5\% of cases and tend to appear at young ages.

Dyskeratosis congenita is a disorder of telomere homeostasis. Alterations in genes associated with telomere function (Dyskeratosis Congenita 1 [DKC1], Telomerase RNA Component [TERC], TERF1 [TRF1]-interacting nuclear factor 2 [TINF2], NHP2 ribonucleoprotein homolog (yeast) [NHP2], NOP10 ribonucleoprotein homolog (yeast) [NOP10], Telomerase reverse transcriptase [TERT] result in shortening of telomeres and defects in proliferation and spontaneous chromosomal rearrangements. ${ }^{34}$

\section{Bloom Syndrome}

Bloom syndrome (BS) is a rare autosomal recessive disease characterized by severe growth retardation, recurrent infections, diabetes, chronic pulmonary disease, and a predisposition to cancer development. Patients present early in life with a characteristic erythematous telangiectatic, scaly rash on sun-exposed areas. Other cutaneous features include hypo- and hyperpigmented areas, café-au-lait spots, and telangiectasias. Affected individuals are at a high risk of early onset cancer development, including leukemias, lympho- mas, and solid tumors. Cutaneous SCC accounts for 14\% of all tumors in BS patients, occurring at a mean age of 31.8 years. ${ }^{35}$

Mutations in the DNA helicase RecQ protein-like-3 gene (RECQL3) have been identified in patients with BS. The gene encodes a protein that is important in maintaining the stability of the DNA during the replication process. Lack of the BLM protein or protein activity destabilizes other enzymes that participate in DNA replication and repair. ${ }^{36,37}$

\section{Werner Syndrome}

Werner syndrome (WS) is a rare premature aging disease transmitted as an autosomal recessive trait. Patients appear with short stature, premature graying of hair, baldness, bilateral ocular cataracts, type 2 diabetes mellitus, and muscular atrophy. Skin findings include pigmentation changes, atrophy, sclerodermatous skin changes, regional atrophy of subcutaneous fat, and ulcerations around the Achilles tendon. Patients with WS have a shorter lifespan with an average life expectancy $<50$ years and increased susceptibility to cancer. ${ }^{38}$ Soft tissue sarcomas and benign meningiomas have been associated with WS, whereas $20 \%$ of the malignancies reported are cutaneous, with SCC accounting for the majority of the latter. The gene underlying WS (Werner syndrome [WRN] gene) is located on chromosome 8p12-p11.2 and encodes for a protein that is a member of the RecQ family of DNA helicases. Mutations in the WRN gene result in a truncation of the protein translation and a loss of the nuclear localization, which are essential in performing their functional interactions. ${ }^{39}$ The $1136 \mathrm{C}-\mathrm{T}$ WRN mutation is the most common mutation detected in $25 \%$ of white populations. ${ }^{40}$

\section{Conclusions}

The diagnosis of nonmelanoma skin cancer at an early age often conceals an underlying hereditary trait. Recent technologies and research have shed light on the genetic alterations that lead to those genodermatoses. However, there is a great need for constant clinical awareness in order for dermatologists to promptly diagnose and properly treat such diseases.

\section{References}

1. Rogers HW, Weinstock MA, Harris AR, et al: Incidence estimate of nonmelanoma skin cancer in the United States, 2006. Arch Dermatol 146:283-287, 2010

2. Kimonis VE, Goldstein AM, Pastakia B, et al: Clinical manifestations in 105 persons with nevoid basal cell carcinoma syndrome. Am J Med Genet 69:299-308, 1997

3. Shanley S, Ratcliffe J, Hockey A, et al: Nevoid basal cell carcinoma syndrome: Review of 118 affected individuals. Am J Med Genet 50: 282-290, 1994

4. Goldstein AM, Pastakia B, DiGiovanna JJ, et al: Clinical findings in two African-American families with the nevoid basal cell carcinoma syndrome (NBCC). Am J Med Genet 50:272-281, 1994

5. Lo Muzio L, Nocini PF, Savoia A, et al: Nevoid basal cell carcinoma syndrome. Clinical findings in 37 Italian affected individuals. Clin Genet 55:34-40, 1999

6. Kolm I, Puig S, Iranzo P, et al: Dermoscopy in Gorlin-Goltz syndrome. Dermatol Surg 32:847-851, 2006 
7. Wilson LC, Ajayi-Obe E, Bernhard B, et al: Patched mutations and hairy skin patches: A new sign in Gorlin syndrome. Am J Med Genet A $140: 2625-2630,2006$

8. Gu XM, Zhao HS, Sun LS, et al: PTCH mutations in sporadic and Gorlin-syndrome-related odontogenic keratocysts. J Dent Res 85:859863,2006

9. Tsao H: Genetics of nonmelanoma skin cancer. Arch Dermatol 137: 1486-1492, 2001

10. Hahn H, Wicking C, Zaphiropoulous PG, et al: Mutations of the human homolog of Drosophila patched in the nevoid basal cell carcinoma syndrome. Cell 85:841-851, 1996

11. Lindström E, Shimokawa T, Toftgård R, et al: PTCH mutations: Distribution and analyses. Hum Mutat 27:215-219, 2006

12. Jones EA, Sajid MI, Shenton A, Evans DG: Basal cell carcinomas in Gorlin syndrome: A review of 202 patients. J Skin Cancer 2011:217378, 2011

13. Michaëlsson G, Olsson E, Westermark P: The Rombo syndrome: A familial disorder with vermiculate atrophoderma, milia, hypotrichosis, trichoepitheliomas, basal cell carcinomas and peripheral vasodilation with cyanosis. Acta Derm Venereol 61:497-503, 1981

14. Ashinoff R, Jacobson M, Belsito DV: Rombo syndrome: A second case report and review. J Am Acad Dermatol 28:1011-1014, 1993

15. van Steensel MA, Jaspers NG, Steijlen PM: A case of Rombo syndrome. Br J Dermatol 144:1215-1218, 2001

16. Abuzahra F, Parren LJ, Frank J: Multiple familial and pigmented basal cell carcinomas in early childhood-Bazex- Dupré-Christol syndrome. J Eur Acad Dermatol Venereol 26:117-121, 2012

17. Vabres P, Lacombe D, Rabinowitz LG, et al: The gene for Bazex-DupréChristol syndrome maps to chromosome Xq. J Invest Dermatol 105: 87-91, 1995

18. Oley CA, Sharpe H, Chenevix-Trench G: Basal cell carcinomas, coarse sparse hair, and milia. Am J Med Genet 43:799-804, 1992

19. Andreani V, Richard M, Folchetti G, et al: Congenital hypotrichosis and milia with spontaneous regression during adolescence or Oley syndrome: A variant of Bazex-Dupre-Christol syndrome [in French]. Ann Dermatol Venereol 127:285-288, 2000

20. Goudie DR, D'Alessandro M, Merriman B, et al: Multiple self-healing squamous epithelioma is caused by a disease-specific spectrum of mutations in TGFBR1. Nat Genet 43:365-369, 2011

21. Wang LL, Levy ML, Lewis RA, et al: Clinical manifestations in a cohort of 41 Rothmund-Thomson syndrome patients. Am J Med Genet 102: $11-17,2001$

22. Wang LL, Gannavarapu A, Kozinetz CA, et al: Association between osteosarcoma and deleterious mutations in the RECQL4 gene in Rothmund-Thomson syndrome. J Natl Cancer Inst 95:669-674, 2003

23. Alter BP: Cancer in fanconi anemia, 1927-2001. Cancer 97:425-440, 2003
24. Tischkowitz M, Dokal I: Fanconi anaemia and leukaemia—Clinical and molecular aspects. Br J Haematol 126:176-191, 2004

25. De Kerviler E, Guermazi A, Zagdanski AM, et al: The clinical and radiological features of Fanconi's anaemia. Clin Radiol 55:340-345, 2000

26. Brilliant $\mathrm{MH}$ : The mouse $\mathrm{p}$ (pink-eyed dilution) and human $\mathrm{P}$ genes, oculocutaneous albinism type 2 (OCA2), and melanosomal pH. Pigment Cell Res 14:86-93, 2001

27. Luande J, Henschke CI, Mohammed N: The Tanzanian human albino skin. Natural history. Cancer 55:1823-8, 1985

28. Bruckner-Tuderman L: Hereditary skin diseases of anchoring fibrils. J Dermatol Sci 20:122-133, 1999

29. Fine JD, Johnson LB, Suchindran C, et al: Cancer and inherited epidermolysis bullosa: lifetable analyses of the national epidermolysis bullosa registry study population, in Fine JD, Bauer EA, McGuire J, et al (eds): Epidermolysis Bullosa: Clinical, Epidemiologic, and Laboratory Advances, and the Findings of the National Epidermolysisbullosa Registry. Baltimore, Johns Hopkins University Press; 1999, pp 175-92

30. Fine JD, Johnson LB, Weiner M, et al: Cause-specific risks of childhood death in inherited epidermolysis bullosa. J Pediatr 152:276-280, 2008

31. Fine JD, Mellerio JE: Extracutaneous manifestations and complications of inherited epidermolysis bullosa: Part I. Epithelial associated tissues. J Am Acad Dermatol 61:367-384, 2009

32. Nq YZ, Pourreyron C, Salas-Alanis JC, et al. Fibroblast-derived dermal matrix drives development of aggressive cutaneous squamous cell carcinoma in patients with recessive dystrophic epidermolysis bullosa. Cancer Res, in press

33. Ramoz N, Rueda LA, Bouadjar B, et al: Mutations in two adjacent novel genes are associated with epidermodysplasia verruciformis. Nat Genet 32:579-581, 2002

34. Batista LF, Pech MF, Zhong FL, et al: Telomere shortening and loss of self-renewal in dyskeratosis congenita induced pluripotent stem cells. Nature 474:399-402, 2011

35. German J: Bloom's syndrome. XX. The first 100 cancers. Cancer Genet Cytogenet 93:100-106, 1997

36. Ellis NA, Groden J, Ye TZ, et al: The Bloom's syndrome gene product is homologous to RecQ helicases. Cell 83:655-666, 1995

37. Bugreev DV, Yu X, Egelman EH, et al: Novel pro- and anti-recombination activities of the Bloom's syndrome helicase. Genes Dev 21:30853094, 2007

38. Yamamoto K, Imakiire A, Miyagawa N, et al: A report of two cases of Werner's syndrome and review of the literature. J Orthop Surg (Hong Kong) 11:224-233, 2003

39. Suzuki T, Shiratori M, Furuichi Y, et al: Diverged nuclear localization of Werner helicase in human and mouse cells. Oncogene 20:2551-2558, 2001

40. Friedrich K, Lee L, Leistritz DF, et al: WRN mutations in Werner syndrome patients: Genomic rearrangements, unusual intronic mutations and ethnic-specific alterations. Hum Genet 128:103-111, 2010 